\title{
Metallic fabric jackets: an innovative method for seismic retrofitting of substandard RC prismatic members
}

\author{
By G.E Thermou' and S.J. Pantazopoulou²
}

\begin{abstract}
This paper presents the results of a recent experimental research study where metallic (high strength steel cord) fabric jackets (MF jackets) were utilized for the seismic upgrading of substandard reinforced concrete members. The proposed intervention method and its practical application are described in detail. Specimens were cantilevers with a square cross section, representing a typical building column at half scale. The length of the test region corresponded to half the span of a typical storey building column under lateral sway. Due to lack of adequate seismic detailing the specimens were susceptible to various modes of failure such as web shear failure, buckling of compression reinforcement or failure in the lap splice region. The as-built specimens were first damaged up to failure after being subjected to combined axial loading and cyclic lateral displacement reversals simulating seismic loading. In the next phase, specimens were retrofitted with both composite and metallic fabric jackets and then tested again under the same load history. The results of this preliminary experimental research program show that the metallic fabric jackets performed in an excellent way compared to G- and C-FRP jackets, increasing substantially both the strength and the deformation capacity of the repaired members. The excellent mechanical performance of the metallic fabrics combined with many of the advantages of the synthetic wraps (easy handling, no change in member dimensions) and the intrinsic favourable properties of steel (fire resistance), underline the potential of this novel material in repair/strengthening of reinforced concrete as an alternative option for jacketing applications.
\end{abstract}

Keywords: Reinforced concrete; seismic upgrading; repair; retrofit; metallic fabrics; jackets; steel cord

\footnotetext{
${ }^{1}$ PhD Candidate, Civil Eng. Dept., Demokritus Univ. of Thrace, Greece, email: gthermou@otenet.gr 2 Professor, Civil Eng. Dept., Demokritus Univ. of Thrace, Greece, email: pantaz@civil.duth.gr, tel/fax: +30 2541079639
} 


\section{INTRODUCTION}

Earthquakes worldwide have repeatedly demonstrated the poor seismic performance of old, substandard reinforced concrete construction. Retrofitting is the only viable option in order to upgrade the level of seismic protection provided by the existing building stock. The evolution of material technology has contributed towards this direction. Nowadays, Fiber Reinforced Polymer (FRP) jacketing is used extensively worldwide as a fast and efficient retrofit solution through jacketing of substandard reinforced concrete members. A new intervention method is introduced in this paper where instead of FRP fabrics, metallic fabrics that consist of high strength steel cords are utilized. The metallic fabrics combined with cementitious grout that serves as the connecting matrix, create a new composite system that is simple and fast in its application. In this paper the technology of the proposed method and the application procedure entailed are described in detail.

An experimental program was conducted in order to identify the efficiency of metallic fabrics (MF) as jacketing devices for reinforced concrete. Five half-scale reinforced concrete columns were tested under combined axial load and a reversed cyclic lateral displacement history simulating earthquake effects. Prior to retrofitting, specimens were first damaged under combined axial compression and reversed cyclic shear-flexure up to failure. The specimens were representative of older construction practices having poor reinforcement detailing such as insufficient transverse reinforcement (inadequately anchored, sparse stirrups, smooth bars) and lap-splices in the plastic hinge region. The metallic fabric jackets were applied to three of the available specimens, whereas glass- and carbon-FRP jackets were applied respectively to the other two specimens for comparison. The retrofit procedure and the behaviour of the retrofitted specimens are described in detail in the paper. Test results demonstrate the effectiveness of the introduced intervention method compared to established methods such as G- and C-FRP jacketing.

\section{EXPERIMENTAL PROGRAM}

\section{Test setup; specimen geometry; test parameters}

The experimental program included five test assemblies each of which comprised one specimen tied back to back with a dummy column of identical external geometry including the footing stub, which was however much stronger than the test specimen (Fig. 1). This support specimen was reused to conduct all the tests and underwent negligible damage throughout the experimental program. The system of the two specimens (test and support) resembles a simply supported beam with a stub in the 
center. All assemblies were tested with simple hinge supports at their ends. Transverse load was applied through the middle stub under displacement control using a predefined history of displacement reversals. Axial load was applied directly on the metal cap through a pinned support; in these cases the axial load was applied to its full magnitude first and was subsequently maintained at that level while the system was cycled in the transverse direction. The reason why there was no monolithic connection between the test column and the support column was so as to achieve realistic bond conditions and anchorage of the longitudinal bars in the test column. The relative displacements were measured for both the test and the support specimen from fixed reference points using Linear Variable Displacement Transducers (LVDTs).

The square cross section cantilever specimens are representative of a typical building column from column mid-height between floors to the beam-column connection at a scale of 1:2. The specimens were designed without seismic detailing, and were representative of typical construction found in reinforced concrete frames in Southern Europe dating from the 1970's. The geometry and reinforcement detailing of a typical column and support column are illustrated in Figure 2 . The crosssectional dimension was $200 \mathrm{~mm}$ square and the length of the shear span, $L_{s}$, was $900 \mathrm{~mm}$. The longitudinal reinforcement consisted of $8 \varnothing 12, \mathrm{~S} 500$ bars distributed uniformly around the perimeter of the cross-section, with a clear cover of approximately $15 \mathrm{~mm}$. The nominal concrete compressive strength was $f_{c k}=20 \mathrm{MPa}$ (Table 1). Transverse reinforcement comprised smooth steel, rectangular shaped stirrups of nominal diameter Ø6, S220. Stirrup ends were simply lapped at the corner. Reinforcement details of specimens are depicted in Figure 2.

Dimensioning and detailing of the old-type specimens followed the German DIN 1045 which was the design code used extensively in Europe from 1960's up to the mid-eighties. The materials used for the construction of the test specimens followed the requirements for seismic applications; primary reinforcement should be StIllb, stirrups should be at least Stl and concrete quality should be at least B225 (corresponding to a nominal concrete strength of $16 \mathrm{MPa}$ - classified as C16 in EC2). The stirrups used were smooth bars $\varnothing 6$ having a nominal yield strength of 220MPa (S220), which corresponds to Stl. The longitudinal bars had nominal yield strength of $500 \mathrm{MPa}$ (S500) that corresponds to steel quality Stlllb. The nominal compressive strength of concrete $f_{c k}=20 M P a$, i.e., within the range of values recommended in the period of interest.

In the present study, the original specimens were designed so as to develop various brittle or 
semi-brittle modes of failure in order to simulate the performance of older structures with poor detailing in strong earthquakes. Here, test specimens were constructed in a scale of 1:2. Thus, the $8 \varnothing 12$ used as longitudinal reinforcement in the $200 \mathrm{~mm}$ square cross-section corresponded to a percentage of longitudinal reinforcement of $\rho_{s}=2.26 \%$. As an area ratio of steel, this is within the range encountered in the lower-storey columns of medium rise residential buildings; in the full-scale reference column, the cross section would be $400 \mathrm{~mm}$ square, reinforced with 12020 . According with DIN1045, the maximum value of longitudinal reinforcement $\rho_{s, \max }$ given as a percentage over the statically required concrete section should be $\rho_{s, \max }=6 \%$. The minimum stirrup bar diameter was $\varnothing 5$ and the maximum stirrup spacing $s_{\max }$ would be the minimum of the cross-section size and 12 times the longitudinal bar diameter (i.e. $12 \times 20=240 \mathrm{~mm}$. In the scaled specimen this is $120 \mathrm{~mm}$ ).

To encourage the occurrence of a particular sequence of failure which was the study objective, the Capacity-Based Prioritizing framework ${ }^{1}$ was applied in the design of the old-type specimens. In this framework the strength of a substandard specimen may be controlled by a number of alternative modes of failure that may occur either prematurely or may prevail after flexural yielding but before attainment of the ultimate flexural capacity which is the classical mode anticipated in modern design. In the absence of well detailed stirrups, as in the case of the test specimens (smooth Ø6, S220, open stirrups), either a shear failure, or failure in the lap splice region could occur before or even after flexural yielding. In case that the dependable shear strength was sufficient to support flexural response at large ductility demands, then lap-splice failure could prevail. This type of behavior is entirely controlled by stirrup spacing. Thus, specimens tested in this series with a very sparse arrangement of stirrups (with stirrup spacing equal to $110 \mathrm{~mm}^{2}$ ) failed abruptly in shear after flexural yielding. In the case of the lap-spliced specimens ( $\left.L 36 D_{b} \_a, L 36 D_{b} \_b, L N 36 D_{b \_} a\right)$, the specimen design objective was to produce failure in the lap-splice region after flexural yielding. The stirrup spacing was determined at $70 \mathrm{~mm}\left(\approx 6 D_{b}\right)$, which was enough to avoid shear failure, but also to prevent early post-yield buckling of longitudinal bars (based on results from past research ${ }^{3,4,5}$, when stirrup spacing exceeds $6 \div 8 D_{b}$, buckling of longitudinal reinforcement may occur before the concrete core may even mobilize the full confining action of the ties.) The stirrup spacing in case of specimens FN_a and FN_b was defined at $50 \mathrm{~mm}\left(\approx 4 D_{b}\right)$ since the design for those specimens was aimed at a flexure-controlled behaviour. 
Specimen identification codes denote the intended mode of failure $(F$ for flexural mode, $L$ for Lap-splice failure; in the latter the numeral $36 \mathrm{D}_{\mathrm{b}}$ represents the length of the splice given in multiples of the main bar diameter, $\mathrm{Db}_{\mathrm{b}}$ ), $\mathrm{N}$ indicates that axial load has been applied (when this was the case, $\mathrm{N}$ was $8 \%$ of the column squashing load $A_{g} f_{c}{ }^{\prime}$, in the range of 6 tons), whereas index $a$ or $b$ marks the loading history type considered. Spacing of the transverse reinforcement was differentiated from $50 \mathrm{~mm}$ to $70 \mathrm{~mm}$. A summary of the properties of the test units is presented in Table 1.

The specimens were subjected to two alternative types of displacement histories, "a" and "b". In both histories the displacement amplitude was given as fraction of the estimated tip yield displacement of the specimens, $\Delta_{y}(=14 \mathrm{~mm})$. Three-cycle increments were applied at each displacement level in both directions. In particular for displacement history "a", the increase of displacement from cycle to cycle was $0.25 \Delta_{y}, 0.50 \Delta_{y}, 0.75 \Delta_{y}, 1.00 \Delta_{y}, 1.50 \Delta_{y}, 2.00 \Delta_{y}, 2.50 \Delta_{y}$, continuing up to $4.0 \Delta_{\mathrm{y}}$. In displacement history "b" which resembled near field earthquake effects displacement was increased significantly from cycle to cycle with a sudden large pulse following the 2 $\Delta_{y}$ cycle $\left(0.50 \Delta_{y}, 1.00 \Delta_{y}, 2.00 \Delta_{y}\right.$-one cycle, $\left.5.00 \Delta_{y}\right)$. The same types of displacement histories were used to test specimens both before and after retrofit. Displacement capacity was associated with a $20 \%$ drop of strength in the post-peak branch of the envelope curve drawn by connecting the peak points of the experimental hysteresis loops.

The main objective of this experimental study was to assess the potential of using metallic fabric (high strength steel cords) jackets as an alternative strengthening system to FRP jackets (glass or carbon). The primary benefit of the steel chord as compared with the glass or carbon fiber lies foremost in the redundancy of the system which is partly owing to the use of a cementitious matrix rather than epoxy. Other benefits are, the better resistance to fire (the jacket is immersed in the cementitious matrix and it is not externally bonded, so it is protected better than the conventional FRP jacket) and the greater familiarity that structural engineers have with steel. A secondary objective was to investigate the influence of the type of applied displacement history on the response of the retrofitted specimens. In light of the above, specimens were divided into two groups based on the parameter under investigation. The first group comprised lap-spliced specimens all tested with displacement history "b" where the parameter under investigation was the comparative effectiveness of the three alternative methods of jacketing; glass-, carbon-FRP jackets vs metallic fabric jackets (RgLN36D $D_{b} b$, RcLN36D b_b, RmLN36D $D_{b} b$ ). The second group, comprising specimens FN_a and 
FN_b both retrofitted with metallic fabric jackets, were subjected to displacement histories "a" and "b", in order to investigate the response of this innovative composite system to the different displacement histories.

The as-built specimens were first damaged up to failure after being subjected to simulated seismic loading. In the next phase, the pre-damaged specimens were retrofitted and then loaded again under cyclic lateral displacement reversals simulating earthquake effects with constant axial load.

\section{Materials used in retrofitting}

Both glass and carbon unidirectional fiber systems were used in the retrofit procedure. The properties of the FRP plies and of the epoxy matrix utilized are presented in Table 2 and Table 3, respectively. Two types of high carbon steel cords with a micro-fine brass also known as AO-brass (Adhesion Optimised) coating were utilized. The $12 \mathrm{X}$ wire cord is made by twisting two different individual wire diameters together in 12 strands with over twisting 1 wire around the bundle (Fig. 3a). The 3X2 wire cord is made by twisting 5 individual wires together -3 straight filaments wrapped by 2 filaments at a high twist angle (Fig. 3b). The density of both $3 X 2$ and 12X consisted of 9.06 cords per centimetre, which is considered high density tape. The geometrical and mechanical properties of single roving (cord) are summarized in Table 4. Cementitious grouts played a double role in the retrofit procedure (Table 5). They were used as pour material to replace damaged (spalled) concrete. Moreover, they were used as substrate material for the application of the metallic fabric jackets.

\section{BEHAVIOUR OF EXISTING MEMBERS}

The retrofit design was based on the behaviour of the existing members which were tested up to failure prior to repair. Specimens $L 36 D_{b} \_a$ and $L 36 D_{b} \_b$ were tested without axial compression. At the attainment of ductility $\mu_{\Delta}=2$ the lap-splice failed with wide longitudinal cracks running over the lapped region in the compression and tension faces of the element (Fig. 4). Specimen $L 36 D_{b} \_a$ completed 3 cycles at a ductility level of $\mu_{\Delta}=2.0$, whereas specimen $L 36 D_{b} \_b$ completed 1 cycle at ductility $\mu_{\Delta}=5.0$. The mode of failure of specimen $L N 36 D_{b} \_a$ was markedly different from that observed in the other lap-spliced columns, due to the influence of the axial loading. During the initial cycles of loading (up to a ductility of $\mu_{\Delta}=1.5$ ), flexural cracking was observed, with a predominant crack forming around the perimeter of the column cross-section at the face of the foundation block. With increasing ductility 
demand damage was concentrated in the plastic hinge region. In the end of the test (after completing 3 cycles at ductility $\mu_{\Delta}=2.5$ ) the bottom row of longitudinal reinforcing bars buckled within the first stirrup spacing (Fig. 4). Specimen FN_a exhibited initially a flexure-controlled behaviour up to the first cycle at ductility $\mu_{\Delta}=1.5$. From that point onwards the behaviour became increasingly controlled by shear action, marked by diagonal cracking and damage accumulation in the plastic hinge zone. At the end of the first cycle with ductility $\mu_{\Delta}=2.5$, the nominal deformation capacity of the specimen had been exhausted (marked by $20 \%$ unrecoverable loss of strength past the peak point in the envelope). At that point the test was terminated so that repair could be viable (Fig. 5). In case of specimen FN_b, the behaviour was flexure controlled up to the first cycle at ductility $\mu_{\Delta}=1.0$. In the following cycles, the behaviour was dominated by shear (diagonal cracking and disintegration). Failure was attained at the end of first cycle at a ductility $\mu_{\Delta}=5.0$ (Fig. 5).

\section{DESIGN OF RETROFIT SCHEMES}

The retrofit design in case of specimens $L 36 D_{b} \_a$ and $L 36 D_{b} \_b$ was intended to alleviate the likelihood of failure in the lap-splice region. FRP jacketing was the intervention method selected for these two specimens: $L 36 D_{b} \_a$ was retrofitted using glass fabric and is referred to hereon as Rg_LN36D $b \_b$ (R stands for retrofitted, g: glass-FRP, _b refers to the displacement history used in testing the retrofitted specimen). $L 36 D_{b} \_b$ was retrofitted with carbon wraps and is referred to hereon as Rc_LN36Db_b (c: carbon-FRP). The jackets were wrapped externally so that the fibers were oriented normal to the anticipated splitting cracks over a length of $400 \mathrm{~mm}$ from the support (this length was sufficient to cover the lap-spliced region).

The number of FRP plies required was determined based on a methodology developed by Pantazopoulou and Tastani ${ }^{6}$ for repair/strengthening of anchorage/lap splices in reinforced concrete using externally bonded FRP jackets. The required bond stress, $f_{b}$ dem, for a lap-splice length, $L_{b}$, is estimated from:

$f_{b}^{\text {dem }}=\frac{D_{b} f_{y}}{4 L_{b}}=\frac{12 \cdot 500}{4 \cdot 430}=3.5 \mathrm{MPa}$

where $D_{b}(=12 \mathrm{~mm})$ the bar diameter, $f_{y}(=500 \mathrm{MPa})$ the yield strength of steel and $L_{b}\left(=36 \mathrm{D}_{b}=430 \mathrm{~mm}\right)$ the anchorage length. The average bond stress $f_{b, d}$ developing along the lateral surface of the bar equals: 
$f_{b}^{\text {dem }}=\bar{\mu} \frac{1}{\pi D_{b}}\left(\sigma_{\text {lat }}^{c}+\frac{\sigma_{\text {lat }}^{f}}{N_{b}}\right) \Rightarrow \frac{\sigma_{\text {lat }}^{f}}{N_{b}}=\frac{f_{b}^{\text {dem }} \pi D_{b}}{\bar{\mu}}-c f_{t}^{\prime}=\frac{3.5 \cdot 3.14 \cdot 12}{1.8}-15 \cdot 1.5=50 \mathrm{MPa}$

where $\bar{\mu}=2 \mu \square$ and $\mu \square$ is the coefficient of friction at the steel-concrete interface taken equal to $0.9 \div 1$, $N_{b}(=8)$ is the number of bars (or pairs of spliced bars) laterally restrained by the transverse pressure, $D_{b}(=12 \mathrm{~mm})$ the bar diameter and $\sigma_{l a t}{ }^{c}, \sigma_{l a t}{ }^{f}$ the radial pressure exerted upon the lateral surface of the bar by the concrete cover and jacketing reinforcement, respectively. $c(=15 \mathrm{~mm})$ is the concrete cover, $f_{t}^{\prime}(=1.5 \mathrm{MPa})$ the tensile strength of concrete, $k_{f}^{\text {anch }}(=1)$ is the effectiveness coefficient for the jacket, $n t_{f}$ is the jacket thickness $\left(t_{f}=0.36 \mathrm{~mm}\right), E_{f}(=76000 \mathrm{MPa})$ is the elastic modulus of the FRP wrap, $b(=200 \mathrm{~mm})$ is the cross-section width (orthogonal to the applied shear force). The number of the FRP layers is defined as:

$$
\frac{\sigma_{\text {lat }}^{f}}{N_{b}}=\frac{2 k_{f} n t_{f} E_{f} \varepsilon^{h c}}{N_{b}} \Rightarrow n=\frac{\sigma_{\text {lat }}^{f}}{2 K_{f} t_{f} E_{f} \varepsilon^{h c}}=\frac{(50 \cdot 8)}{2 \cdot 1 \cdot 0.36 \cdot 76000 \cdot 0.0024}=3 \text { layers }
$$

where $\varepsilon^{h c}(=0.0024)$ is the is the surface strain value associated with attainment of peak bond stress along the bar.

The three layers of composite fabric applied in case of specimens RgLN36Db_b and RcLN36Db_b provided resistance to alternative failure modes such as shear and buckling and increased the confinement (increase of deformation capacity). The required number of layers for avoiding the alternative failure modes appears in Table 6. In case of specimen RgLN36D $b$ b, one layer of glass fabric suffices to avoid shear failure and buckling (for ductility level equal to $\mu_{\Delta}=2.5$ ), whereas two layers are required for ductility equal to $\mu_{\Delta}=2.5$. The most critical mode of failure was used to determine the final number of FRP layers applied in the retrofitted specimens (Table 6).

No specific guidelines or directions are currently available regarding detailing of externally bonded metallic fabric jackets as this is a novel application. To maintain similar stiffness as with the carbon jacket in the direction of the main fibers, a single ply of metallic fabric was used in specimens LN36Db_b, FN_a and FN_b. To facilitate immersion of the metallic fabric in the relatively stiff cementitious grout that served as a matrix, the cords in the fabric used were spaced at a lateral distance of $5 \mathrm{~mm}$. 


\section{MECHANICAL CHARACTERISTICS OF THE FRP JACKETED MEMBERS}

The three layers applied in the retrofitted specimens (RgLN36Db_b, RcLN36Db_b) modified the hierarchy of the failure modes with the failure in flexure to occur first (Table 7).

Shear strength: The shear strength $\left(V_{\text {shear }}\right)$ which comprises the concrete shear resistance $\left(V_{c}\right)$ and the shear resistance of the FRP jacket $\left(V_{w}{ }^{\dagger}\right)$ increased significantly, leading to failure in flexure $\left(V_{\text {flex }}<V_{\text {shear }}\right)($ Table 7$)$. The shear resistance of the FRP jacket, $V_{w}{ }^{f}$, given the number of the FRP layers, $n$, is calculated from:

$V_{w}^{f}=2 K_{f}^{c o n f} n t_{f} E_{f} \varepsilon_{f}^{e f f} h$

where $K_{f}^{\text {conf }}$ is the effectiveness coefficient of the jacket, $n$ is the number of FRP layers, $t_{f}$ is the FRP

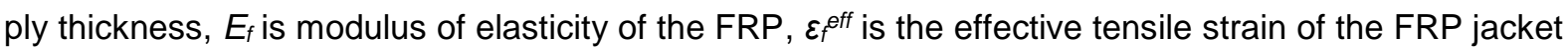
and $h$ is the height of the cross-section.

Confinement - Deformation capacity increase: The three layers provided an increase in the displacement ductility, $\mu_{\Delta}$, due to the significant level of confinement provided. The volumetric ratio of the FRP jacket, $\rho_{f v}$, is calculated given the number of the FRP layers applied:

$\rho_{f v}=\frac{2 n t_{f}(b+h)}{b h}$

where $n$ is the number of FRP layers, $t_{f}$ is the FRP ply thickness and $b, h$ the width and height of the cross-section. The passive confining pressure in the cross-section, $\sigma_{\text {lat }}^{\text {conf }}$, which corresponds to a level of displacement ductility, $\mu_{\Delta}$, is given by:

$\sigma_{\text {lat }}^{\text {conf }}=\frac{1}{2} \frac{\rho_{f v}}{k_{f}^{\text {conf }} E_{f} \varepsilon_{f}^{e f f}}, \mu_{\Delta}=1.3+12.4\left(\sigma_{\text {lat }}^{\text {conf }} / f_{c}^{\prime}-0.1\right)$

where $\rho_{t v}$ is the volumetric ratio of the FRP jacket, $K_{f}^{\text {conf }}$ is the effectiveness coefficient of the jacket, $E_{f}$ is modulus of elasticity of the FRP, $\varepsilon_{f}^{\text {eff }}$ is the effective tensile strain of the FRP jacket and $h$ is the height of the cross-section and $f_{c}^{\prime}$ is the concrete compressive strength.

Confinement - bar buckling delay: In case of bar-buckling delay due to confinement, the passive confining pressure developed, $\sigma_{l a t}{ }^{\text {conf }}$, is estimated based on the curvature ductility, $\mu_{\varphi}$, which is a function of displacement ductility, $\mu_{\Delta}$ :

$$
\sigma_{\text {lat }}^{\text {conf }}=\left[\frac{\left[\left(1.1 \mu_{\varphi}-1\right) \varepsilon_{s y}-0.004\right]}{0.075}+0.1\right] f_{c}^{\prime}, \text { where, } \mu_{\varphi}=\frac{\left(\mu_{\Delta}-1\right) L_{s}}{3 l_{p}\left(1-0.5 \frac{l_{p}}{L_{s}}\right)}+1
$$


where $\varepsilon_{s y}$ is the steel strain at yield, $f_{c}^{\prime}$ is the concrete compressive strength, $L_{s}$ shear span length, $\mu_{\Delta}$ the displacement ductility and $I_{p}$ the plastic hinge length.

\section{RETROFIT PROCEDURE}

\section{Preparation of specimens}

After the first phase of loading, the loose concrete fragments were removed by hand using chisel and hammer. In specimens $L 36 D_{b \_} b, L 36 D_{b} \_a$ and $L N 36 D_{b} \_a$, the concrete core was preserved as shown in Figure 6. However, in specimens FN_a and FN_b, concrete had spalled and disintegrated completely in the damaged area due to the extended crack patterns, and for this reason it was entirely removed (Fig. 7). Success of this phase was critical for the next steps of retrofitting and required caution to avoid damaging the healthy concrete parts and the longitudinal reinforcement and persistence to progress systematically through the complex crack system.

In the next phase moulds were constructed whereby the repairing cementitious high strength grout was poured in the voids created after removal of the concrete fragments (Cementitious grout 1 , Table 4). After casting of the replacement grout, specimens were kept in the moulds for 48 hours. To avoid premature failure of the externally bonded FRP jackets owing to stress concentrations at the specimen's corner, corners were chamfered using a concrete grinder, as recommended for practice ${ }^{7}$. The radius of the rounded corners was in the order of $25 \mathrm{~mm}$. Before the application of the FRP jackets, the surfaces of the repaired specimens were cleaned thoroughly by pressurized air.

\section{$\underline{\text { FRP jackets }}$}

Procedures used for the application of the FRP fabrics followed the manufacturer's directions. The wet lay-up method was used for the application of the glass fabric (Glass, Table 2). The concrete surface was sealed using a primer (Epoxy 2, Table 3) and the dry glass fibers were impregnated by using epoxy resin (Epoxy 1, Table 3). Once saturated, the fabric was wrapped directly on the concrete member. Additional layers were applied while the epoxy on the underlying layer was still tacky. The dry lay-up method was applied in the case of the carbon sheets (Carbon, Table 2). The epoxy resin (Epoxy 2, Table 3) was applied directly onto the substrate (column) as a primer and the fabric was wrapped directly on the concrete member, using a rolling brush to squeeze out the epoxy and any trapped air between the rovings of the fabric. Additional carbon plies were added on the member by applying first the epoxy resin (Epoxy 2, Table 3). Particular attention was placed to secure uniform 
impregnation of the fibers in the epoxy matrix, to eliminate entrapped air voids without wrinkling or distortion of the predominantly hoop directed fibers. The fabric (both glass and carbon) was continuous (three layers $=2.4 \mathrm{~m}$ ) and the last jacket layer was lapped over one full-side of the crosssection as per the manufacturer's instructions for field applications of FRP sheets.

\section{Metallic fabric jackets}

In developing this jacketing procedure the aim was to use familiar materials that are easily accessible while maintaining the simplicity and easy handling of the FRP wraps. To improve impregnation of the metallic fibers in the intended matrix, the structure of the original metallic fabric was modified as shown in Figure 8 to reduce its density; an added objective was to reduce the axial stiffness of the metallic fabric to the level of a carbon sheet. The modified density of both the $3 X 2$ and 12X consisted of 1.85 cords per centimetre, which may be considered a low to medium density. The distance between successive cords was $0.5 \mathrm{~cm}$; thus cords and the supporting plastic net formed a grid of square openings that was considered satisfactory for uninhibited flow of the cementitious grout through the metallic fabric. This was an essential requirement for the success of the method, since grouts are more ductile than epoxy whereas the poor resistance of epoxy to fire and other aggressive agents render its possible replacement by common cementitious grout a desirable goal. Redundant cords were removed manually, paying attention not to damage the underlying net that essentially keeps the cords in position. Prior to its placement the fabric was bent manually with little effort as shown in Figure $8 \mathrm{c}$ in order to facilitate the jacketing application. The procedure used for mounting the metallic fiber jacket is illustrated in steps in Figure 9. After removing the moulds the specimens were in the state shown in Figure 9a. The substrate was saturated with water before proceeding to the application of the cementitious grout. A repairing cementitious high strength grout that could be trowelled (Cementitious grout 2 - Table 5) was applied directly onto the substrate (column). The metallic fabric was placed immediately after each side of specimen was trowelled with the cementitious grout. The grout was squeezed out between the rovings of the fabric by applying pressure manually, using a rolling brush (Fig. 9b). The last jacket layer was lapped over one full-side of the cross-section. A final coat of the cementitious grout was applied to the exposed surface (Fig. 9c). The effect on the geometric dimensions of the jacketed specimens was small - the grout layer including the metallic jackets was $10 \mathrm{~mm}$ thick, so that the final cross-section after retrofit was $220 \mathrm{~mm}$ square. 


\section{TEST RESULTS OF THE RETROFITTED SPECIMENS}

The primary experimental results are summarised in the present section, including observations from the failure mode characteristics and the damage patterns recorded on the specimens.

$\mathbf{R g L N} 36 \mathbf{D}_{\mathbf{b} \_} \mathbf{b}$ : In the early stages of loading $\left(\mu_{\Delta}=0.5\right)$, cracks formed at the connection between the retrofitted specimen and the footing which continued around the perimeter of the cross-section of the cantilever. In the subsequent displacement cycles damage was localised in this area with increasing displacement. No damage was observed on the glass fabric. Actually, the glass fabric prevented the development of diagonal cracks in the jacketed region, so that no actual plastic hinge was visible, whereas bar pullout prevailed. The experiment was terminated at the second cycle of $\mu_{\Delta}=5.0$ since a $20 \%$ drop of strength was observed (Figure 10a). The load vs. displacement diagram for the system of the two (retrofitted and support) specimens is shown in Figure 12a. The maximum load in both directions of loading was reached at the cycle with ductility $\mu_{\Delta}=2.0$. The behaviour of the system with the retrofitted specimen is compared to the original one in Figure 12a. The glass-FRP wrapping successfully increased both the strength and deformation capacity of the entire system.

RcLN36Db_b: The behaviour of specimen RcLN36Db_b resembled that of specimen RgLN36Db_b. The same pattern of cracks was observed, which started to form during the first cycle at ductility $\mu \Delta=1.0$. As in the case of glass fabric, the carbon fabric prevented the development of a plastic hinge region and pullout was observed. The experiment was terminated in the second cycle at $\mu_{\Delta}=5.0$ (Figure 10b). The load vs. displacement diagram for the system of the two (retrofitted and support) specimens is shown in Figure 12b. The maximum load in both directions of loading was reached at the cycle with ductility $\mu_{\Delta}=2.0$. Moreover, the behaviour of the system with the retrofitted specimen is compared to the original one in Figure $12 \mathrm{~b}$. The carbon-FRP wrapping improved substantially the behaviour of the retrofitted member over its original response. As in the case of the glass jacket, by suppressing inelastic deformation in the nominal critical region (where a plastic hinge would be expected to form) all inelasticity was localised at the face of the support, thereby increasing the demand and the level of damage in the main bar anchorage inside the footing.

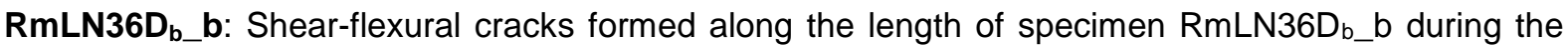
first cycle at ductility $\mu_{\Delta}=1.0$. Additional cracks formed along the concrete cover and at the column to footing connection at ductility $\mu_{\Delta}=2.0$. At that displacement level, the system of the retrofitted and the 
support specimens attained their strength (i.e., peak load). The existing cracks became wider and bar buckling took place at the bottom layer of longitudinal bars during the first cycle at ductility $\mu_{\Delta}=5.0$. Rupture of the bottom corner bar was observed (Figure 11b). Figure 11(a) illustrates the specimen's condition at failure ( $2^{\text {nd }}$ cycle at $\mu_{\Delta}=5.0$ ), whereas Figure 11 (b) focuses in the damaged region after removal of the loose concrete. Although no special measures were taken to improve connection of the external cementitious coating (that served as a matrix for the metallic fabric jacket) with the specimen, no relative slip was observed at the interface. Figure $12 \mathrm{c}$ demonstrates the efficiency of this new composite system (metallic fabric jacket) in improving the behaviour of the existing specimen.

RmFN_a: The first crack formed at the face of the connection of specimen RmFN_a with the footing during the first cycle at ductility $\mu_{\Delta}=0.5$. When the displacement reached the value of $\mu_{\Delta}=1.0$, flexural cracks formed in the front side extending to the back side of the specimen. New cracks formed as the displacement increased till the second cycle at ductility $\mu \Delta=2.5$. From this point onwards, the cracks stabilized and the damage concentrated at the crack that had formed initially at the connection with the footing. The test was terminated after completing the third cycle at ductility $\mu_{\Delta}=4.0$. No actual plastic hinge was visible, whereas bar pullout prevailed. It important to note that due to the significant strength increase of the specimen imparted by the metallic jacket, the upper threshold set for the available load cell was exceeded in the pull direction, thereby limiting the magnitude of transverse displacement that could be further imposed in the pull direction (Figure 14a). Overall the metallic jacket enhanced substantially the behaviour of the system imparting additional strength, enabling the retrofitted element to retain this strength over a large range of deformation (i.e. enhanced its deformation capacity).

RmFN_b: Flexural cracks formed up to the first cycle at $\mu_{\Delta}=1.0$. Some cracks appeared along the concrete cover at displacement $\mu_{\Delta}=2.0$. Damage was detected within the region marked by a deep flexural crack that formed at the second stirrup spacing and the crack formed at the face of the connection with the footing. During the fourth cycle at ductility $\mu_{\Delta}=5.0$, the metallic fabric located within the damaged area was ruptured (Figure 13b). The behaviour of the retrofitted specimen was substantially improved over its original pre-damaged properties but also over the strength and deformation capacity of retrofitted specimens jacketed with FRP wraps (Figure 14b). For one more time the single layer of the metallic fabric jacket proved quite efficient to recover and enhance the available strength and deformation capacity. 
It is evident from the preceding that the retrofitted specimens attained an increased strength and deformation capacity as compared with the original pre-jacketing values. The strength and deformation capacities in both the push and the pull directions are summarised in Table 8 for the retrofitted specimen assemblies as ratios of the respective capacities of each original specimen assembly (an assembly comprises a test specimen tied back to back with a dummy specimen and tested as a simply supported beam under a midpoint load). Displacement capacity in all cases is associated with a $20 \%$ postpeak strength reduction.

The behaviour of the three retrofitted lap-spliced specimens under displacement history $b$ is compared in Figure 15a. The metallic fabric jacket exhibited excellent behaviour compared to the glass- and carbon-FRP jackets. One layer of this composite material (comprising the cementitious grout matrix and the high strength steel cord) sufficed to improve the strength and deformation capacity of the existing member to the same levels as was achieved with the three layers of glassand carbon-FRP jackets. The behaviour of two specimens with identical retrofit, RmFN_a and RmFN_b, under the two different displacement histories, $a$ and b, is compared in Fig. 15b. The higher damage potential displacement history b over that of history a is evident in the results.

\section{SUMMARY AND CONCLUSIONS}

The experimental program conducted comprised five half scale reinforced concrete columns which were tested under reversed cyclic lateral displacements and axial load. The columns which had reinforcement details typical of older construction were damaged before retrofit. An innovative intervention method, the metallic fabric jackets, were applied and compared to the G- and C-FRP jackets. Metallic fabric jackets made of high strength steel cords were utilized in combination with conventional cementitious grouts. The potentiality of this new composite jacketing system as a strengthening/repair procedure was illustrated from the experimental evidence. The behaviour of the retrofitted specimens was modified substantially by altering the modes of failure observed in the predamage state. The retrofitted specimens increased both their strength and deformation capacity. The comparison with the FRP jackets (glass and carbon) demonstrated the efficiency of the metallic jackets. The critical role that the load history has on failure mode, deformation capacity attained and sustained strength was highlighted by the experimental evidence. 


\section{ACKNOWLEDGEMENTS}

This research study was funded by the Hellenic Ministry of Education and Religious Affairs (Graduate Scholarship HRAKLEITOS) and the General Secretariat for Research and Technology (Project ARISTION). The experimental program was conducted in the Laboratory of Reinforced Concrete at Demokritus University of Thrace (DUTh). FRP materials and metallic fabrics were donated by SIKA Hellas. Cementicious grouts were donated by MacBeton Hellas.

\section{REFERENCES}

1. Syntzirma D. V. and Pantazopoulou S. J. Deformation capacity of R.C. members with brittle details under cyclic loads. ACI Special Publication, "Cyclic Shear", edited by ACI Committee 445 (Shear and Torsion), in press, American Concrete Institute, Farmington Hills, MI, USA.

2. Syntzirma D. V. and Pantazopoulou S. J. Assessment of deformability of R.C. members with substandard details. Proceedings of the $2^{\text {nd }}$ International fib Congress, Naples - Italy, June 2006, Paper 9-4.

3. Priestley M., Seible F. and Calvi M. Seismic Design and Retrofit of Bridges. J. Wiley and Sons Inc., New York, 1996, 686.

4. Mau S. Effect of tie spacing on inelastic buckling of reinforcing bars. ACI Structural J., 1999, 87(6), $671-677$.

5. Pantazopoulou S.J. Detailing for reinforcement stability in RC members, ASCE J. of Structural Engineering, 1998, 124(6), 623-632.

6. Tastani, S. P. and Pantazopoulou, S. J. Fiber Reinforced Polymers in Seismic Upgrading of Existing Reinforced Concrete Structures. Proceedings of the 8th U.S. National Conference on Earthquake Engineering (8NCEE), San Francisco - California, April 2006, Paper 232.

7. Fib Bulletin 14. Externally bonded FRP reinforcement for RC structures, Technical Report, 2001, 130. 
Tables:

\section{List of Captions}

Table 1 Geometry and reinforcement details of the test units

Table 2 Nominal material properties of FRP plies

Table 3 Properties of the epoxy matrix used for application of the FRP wraps

Table 4 Mechanical properties of single roving (cord)

Table 5 Characteristics of cementitious grout

Table 6. Required number of layers for mitigating the alternative failure modes

Table 7. Consequences of the number of layers on the mechanical characteristics of the crosssection

Table 8. Strength and deformation capacity for the system of specimens

\section{Figures:}

Figure 1 Test setup

Figure 2 Test assembly: geometry and reinforcement details (dimensions in $\mathrm{mm}$ )

Figure 3 Steel cords (a) 12X; (b) 3X2

Figure 4 Lap-spliced columns at failure

Figure 5 Specimens FN_a and FN_b at failure

Figure 6 Specimens with lap-splices after removal of the loose concrete fragments

Figure 7 Specimens FN_a and FN_b after removal of damaged and fragmented concrete

Figure 8 Metallic fabric 12X (a) at initial condition; (b) after modification; (c) jacket

Figure 9 Steps of the method of application

Figure 10 Specimens (a) RgLN36Db_b; (b) RcLN36Db_b at failure

Figure 11 Specimen $R m L N 36 D_{b} \_b(a)$ at failure; (b) detail of the damaged area

Figure 12 Load-displacement diagrams for the system of specimens Rc-, Rg-, RmLN36Db_b

Figure 13 Specimens (a) RmFN_a; (b) RmFN_b at failure

Figure 14 Load-displacement diagram for the system of specimens RmFN_a and RmFN_b

Figure 15 Load-displacement diagrams for the system of specimens (a) Rc-, Rg-, RmLN36Db_b; (b)

RmFN_a and RmFN_b 
Table 1 Geometry and reinforcement details of the test units

\begin{tabular}{|c|c|c|c|c|c|c|c|c|c|c|}
\hline \multicolumn{5}{|c|}{ Existing specimens } & \multicolumn{6}{|c|}{ Retrofitted specimens } \\
\hline Specimen & $\begin{array}{l}\text { Transverse } \\
\text { reinforcement }\end{array}$ & $\begin{array}{l}\text { Lap- } \\
\text { splice }\end{array}$ & $\begin{array}{c}\text { Axial } \\
\text { load } \\
\left(P / A_{g} f_{c}\right)\end{array}$ & $\begin{array}{l}\text { Load } \\
\text { history }\end{array}$ & Name & $\begin{array}{l}\text { External } \\
\text { reinforcement }\end{array}$ & $\begin{array}{c}\text { Jacket } \\
\text { Height } \\
(\mathrm{mm})\end{array}$ & $\begin{array}{c}\text { No. } \\
\text { of } \\
\text { plies }\end{array}$ & $\begin{array}{c}\text { Axial } \\
\text { load } \\
\left(P / A_{g} f_{c}^{\prime}\right)\end{array}$ & $\begin{array}{l}\text { Load } \\
\text { history }\end{array}$ \\
\hline L36Db_a & $\varnothing 6 / 70$ (open) & $36 D_{b}$ & - & a & Rg_LN36Db_b & Glass $-100 \mathrm{G}$ & 400 & 3 & 0.08 & $b$ \\
\hline L36Db_b & $\varnothing 6 / 70$ (open) & $36 D_{b}$ & - & $b$ & Rc_LN36Db_b & Carbon-200C & 400 & 3 & 0.08 & $b$ \\
\hline LN36Db_a & $\varnothing 6 / 70$ (open) & $36 D_{b}$ & 0.08 & a & Rm_LN36Db_b & $12 X$ & 400 & 1 & 0.08 & $b$ \\
\hline FN_a & $\varnothing 6 / 50$ (open) & - & 0.08 & a & Rm_FN_a & $3 \times 2$ & 600 & 1 & 0.08 & a \\
\hline FN_b & $\varnothing 6 / 50$ (open) & - & 0.08 & $b$ & Rm_FN_b & $3 \times 2$ & 600 & 1 & 0.08 & $b$ \\
\hline
\end{tabular}

Table 2 Nominal material properties of FRP plies

\begin{tabular}{cccccc}
\hline Description & $\begin{array}{c}\text { Thickness } \mathrm{f}_{\mathrm{f}}, \\
\mathrm{mm}\end{array}$ & $\begin{array}{c}\text { Density, } \\
\left(\mathrm{gr} / \mathrm{m}^{2}\right)\end{array}$ & $\begin{array}{c}\text { Tensile strength } \\
\mathrm{f}_{\mathrm{fu}}, \mathrm{MPa}\end{array}$ & $\begin{array}{c}\text { Tensile molulus } \mathrm{E}_{\mathrm{f}}, \\
\mathrm{MPa}\end{array}$ & $\begin{array}{c}\text { Ultimate elongation } \varepsilon_{\mathrm{fu}}, \\
(\mathrm{mm} / \mathrm{mm})\end{array}$ \\
\hline Glass & 0.36 & 935 & 2300 & 76000 & 0.028 \\
Carbon & 0.11 & 200 & 3900 & 230000 & 0.015 \\
\hline
\end{tabular}

Table 3 Properties of epoxy matrix used for application of the FRP wraps

\begin{tabular}{cccc}
\hline Description & $\begin{array}{c}\text { Tensile } \\
\text { strength*, MPa }\end{array}$ & $\begin{array}{c}\text { Flexural } \\
\text { Modulus*, MPa }\end{array}$ & $\begin{array}{c}\text { Elongation*, \% } \\
\text { (Strain at failure) }\end{array}$ \\
\hline Epoxy 1 & 45 & 3000 & 1.5 \\
Epoxy 2 & 30 & 4500 & 0.9 \\
\hline
\end{tabular}

*at 7 days, $23^{0} \mathrm{C}$, DIN 53455

Table 4 Mechanical properties of single roving (cord)

\begin{tabular}{ccccc}
\hline Description & $\begin{array}{c}\text { Filament diameters } \\
(\mathrm{mm})\end{array}$ & $\begin{array}{c}\text { Cord diameter } \\
(\mathrm{mm})\end{array}$ & $\begin{array}{c}\text { Tensile strength } \\
\mathrm{f}_{\mathrm{fu}}, \mathrm{MPa}\end{array}$ & $\begin{array}{c}\text { Strain to failure } \varepsilon_{\mathrm{fu}}, \\
(\mathrm{mm} / \mathrm{mm})\end{array}$ \\
\hline $12 \mathrm{X}$ & $\begin{array}{c}\text { Three } 0.22 \\
\text { nine } 0.20\end{array}$ & 0.889 & 2014 & 0.019 \\
$3 \mathrm{X} 2$ & 0.35 & 0.889 & 2479 & 0.021 \\
\hline
\end{tabular}

Table 5 Characteristics of cementicious grout

\begin{tabular}{cccc}
\hline Description & $\begin{array}{c}\text { Flexural } \\
\text { strength }\end{array}$, MPa & $\begin{array}{c}\text { Compressive } \\
\text { strength*, MPa }^{*}\end{array}$ & $\begin{array}{c}\text { Bonding strength } \\
\text { to steel }\end{array}$, MPa \\
\hline $\begin{array}{c}\text { Cementitious grout 1 } \\
\text { (pour) }\end{array}$ & 6.5 & 55 & 20 \\
$\begin{array}{c}\text { Cementitious grout 2 } \\
\text { (sprayed or trowelled) }\end{array}$ & 7.0 & 60 & 20 \\
\hline
\end{tabular}

*at 7days 
Table 6. Required number of layers for mitigating the alternative failure modes

\begin{tabular}{ccccccc}
\hline Specimen & Type of fabric & Shear & $\begin{array}{c}\text { Confinement } \\
\left(\text { for } \mu_{\Delta}=2.5\right)\end{array}$ & $\begin{array}{c}\text { Buckling } \\
\left(\text { for } \mu_{\Delta}=2.5\right)\end{array}$ & Lap-splicing & Final layers \\
\hline RgLN36D $\mathrm{b}_{\mathrm{b}} \mathrm{b}$ & Glass & 1 layer & 2 layers & 1 layer & 3 layers & 3 layers \\
RcLN36 $\mathrm{D}_{\mathrm{b} \_} \mathrm{b}$ & Carbon & 1 layer & 3 layers & 2 layers & 3layers & 3 layers \\
\hline
\end{tabular}

Table 7. Consequences of the number of layers on the mechanical characteristics of the cross-section

\begin{tabular}{|c|c|c|c|c|c|c|c|c|c|c|}
\hline \multirow{2}{*}{ Specimen } & \multirow{2}{*}{$\begin{array}{c}\text { Number of } \\
\text { layers }\end{array}$} & \multirow{2}{*}{$\begin{array}{c}\text { Flexure } \\
V_{\text {flex }}=M_{\text {flex }} / L_{s}(\mathrm{kN})\end{array}$} & \multicolumn{2}{|c|}{ Shear } & \multicolumn{3}{|c|}{ Confinement } & \multicolumn{3}{|c|}{ Buckling } \\
\hline & & & $V_{w}{ }^{f}(\mathrm{kN})$ & $V_{\text {shear }}=V_{w}{ }^{f}+V_{c}(\mathrm{kN})$ & $\mu_{\Delta}$ & $\sigma_{\text {lat }}^{\text {conf }}(\mathrm{MPa})$ & $\varepsilon_{c c u} / \mu_{\varepsilon c}{ }^{*}$ & $\mu_{\Delta}$ & $\sigma_{\text {lat }}^{\text {conf * }}(\mathrm{MPa})$ & $\mu_{\varepsilon c}{ }^{*}$ \\
\hline RgLN36D $D_{b} b$ & $3 \times$ Glass & 41 & 460 & 470 & 5.0 & 8.0 & $0.0264 / 10.6$ & 9.0 & 8.1 & 14.7 \\
\hline RcLN36D $D_{b \_} b$ & 3xCarbon & 41 & 228 & 238 & 2.5 & 3.9 & $0.0113 / 4.5$ & 3.5 & 4.0 & 4.7 \\
\hline
\end{tabular}

" $\sigma_{\text {lat }}^{\text {conf }}$ : passive confining pressure in the cross-section $\varepsilon_{c c u}$ : failure strain of confined concrete and $\mu_{\varepsilon c}$ : compression strain ductility

Table 8. Strength and deformation capacity for the system of specimens

\begin{tabular}{|c|c|c|c|c|c|c|c|}
\hline \multirow[t]{2}{*}{ Existing } & \multirow[t]{2}{*}{ Retrofitted } & \multicolumn{2}{|c|}{$\begin{array}{l}\text { Strength } \\
\text { capacity }(\%)\end{array}$} & \multicolumn{2}{|c|}{$\begin{array}{l}\text { Deformation } \\
\text { capacity }^{*}(\%)\end{array}$} & \multicolumn{2}{|c|}{$\begin{array}{c}\text { No. of cycles at the upper displacemen } \\
\text { level }\end{array}$} \\
\hline & & Push & Pull & Push & Pull & Existing & Retrofitted \\
\hline FN_a & RmFN_a & 11.8 & 7.4 & 91.7 & 40.9 & 1 cycle $\mu_{\Delta}=2.5$ & 3 cycles $\mu_{\Delta}=4.0$ \\
\hline FN_b & RmFN_b & 30.8 & 2.1 & 45.2 & 78.9 & 1 cycle $\mu_{\Delta}=5.0$ & 4 cycles $\mu_{\Delta}=5.0$ \\
\hline L36D $D_{b \_a}$ & RgLN36D $b \_b$ & 15.2 & 38.9 & 35.6 & 154.6 & 3 cycles $\mu_{\Delta}=2.0$ & 2 cycles $\mu_{\Delta}=5.0$ \\
\hline L36D $D_{b \_} b$ & RcLN36D $b_{b \_b}$ & 27.9 & 42.5 & 339.4 & 107.1 & 1 cycle $\mu_{\Delta}=5.0$ & 2 cycles $\mu_{\Delta}=5.0$ \\
\hline LN36D $D_{b} b$ & RmLN36D $D_{b} b$ & 21.7 & -8.4 & 42.5 & -27.8 & 3 cycles $\mu_{\Delta}=2.5$ & 2 cycles $\mu_{\Delta}=5.0$ \\
\hline
\end{tabular}




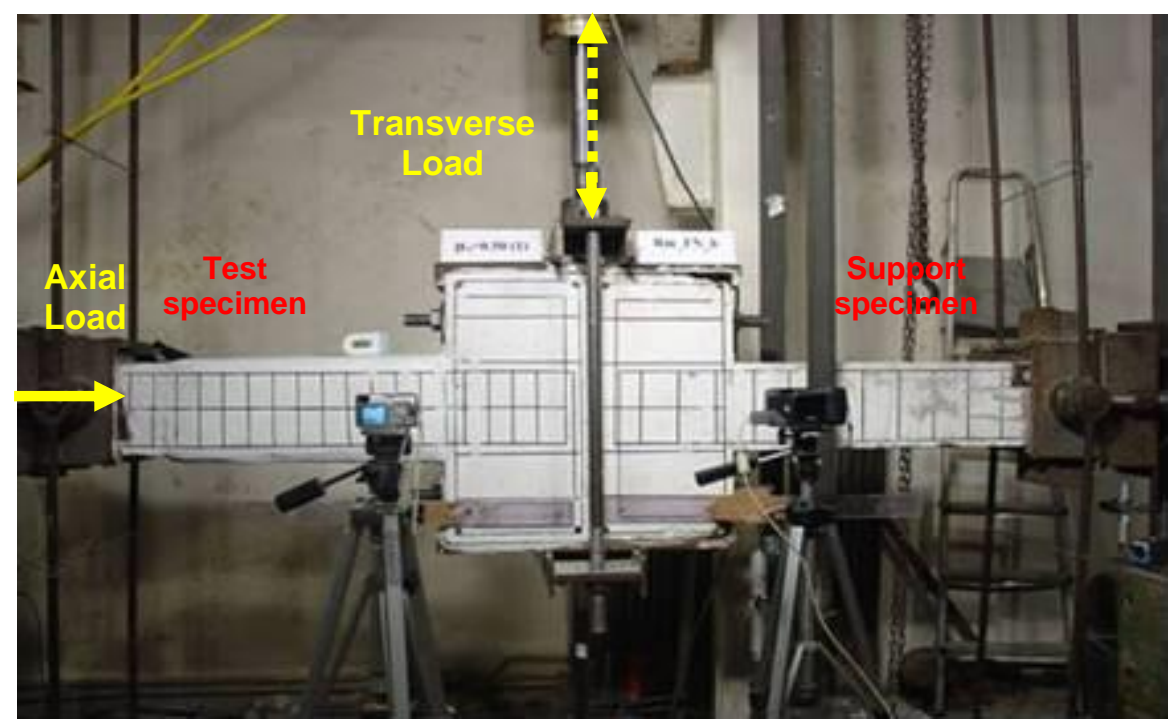

Figure 1 Test setup

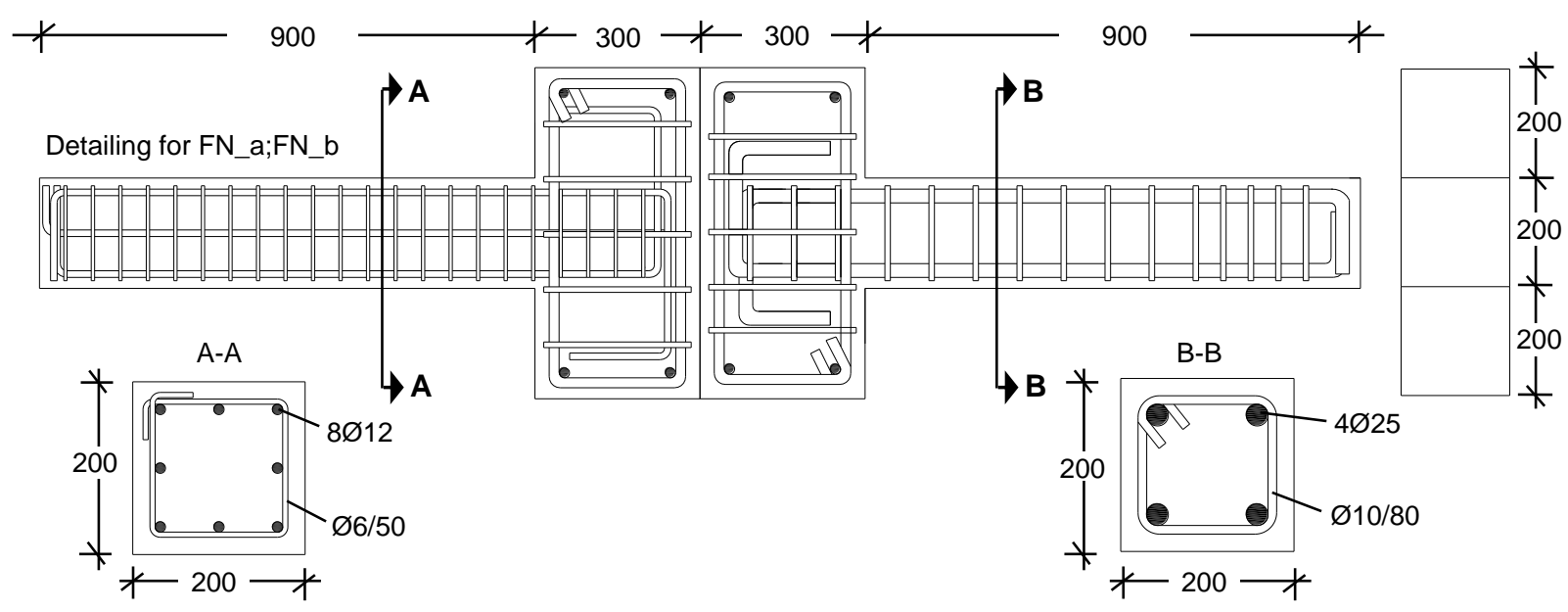

Figure 2 Test assembly: geometry and reinforcement details (dimensions in $\mathrm{mm}$ )

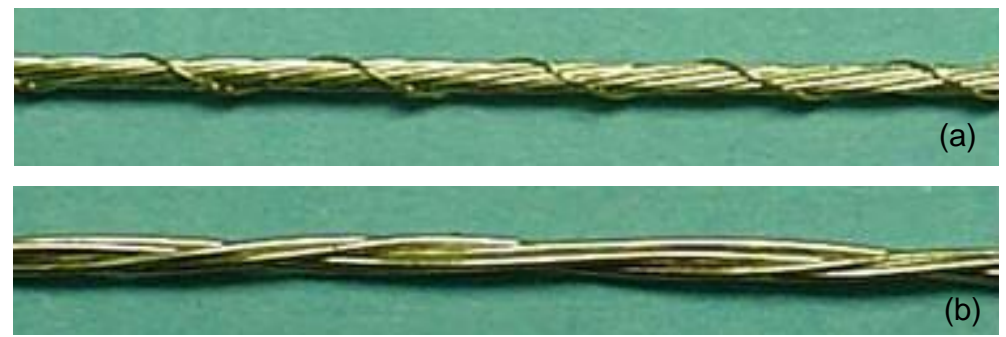

Figure 3 Steel cords (a) 12X; (b) $3 X 2$ 

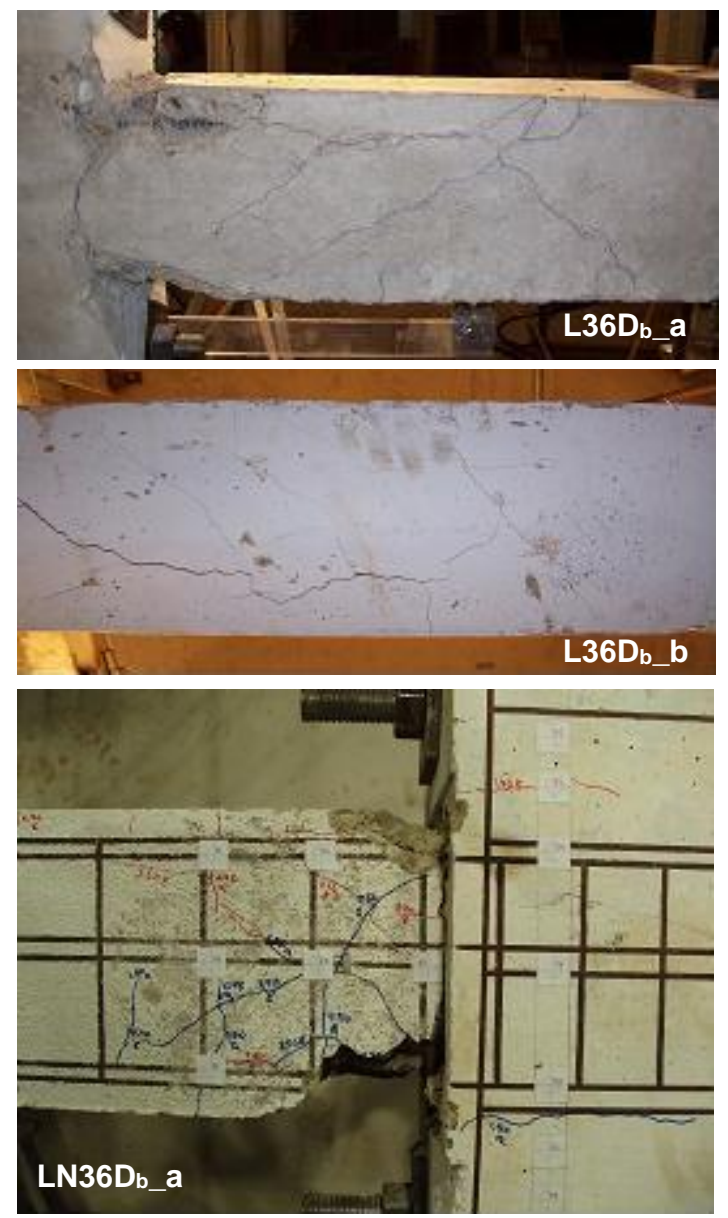

Figure 4 Lap-spliced columns at failure
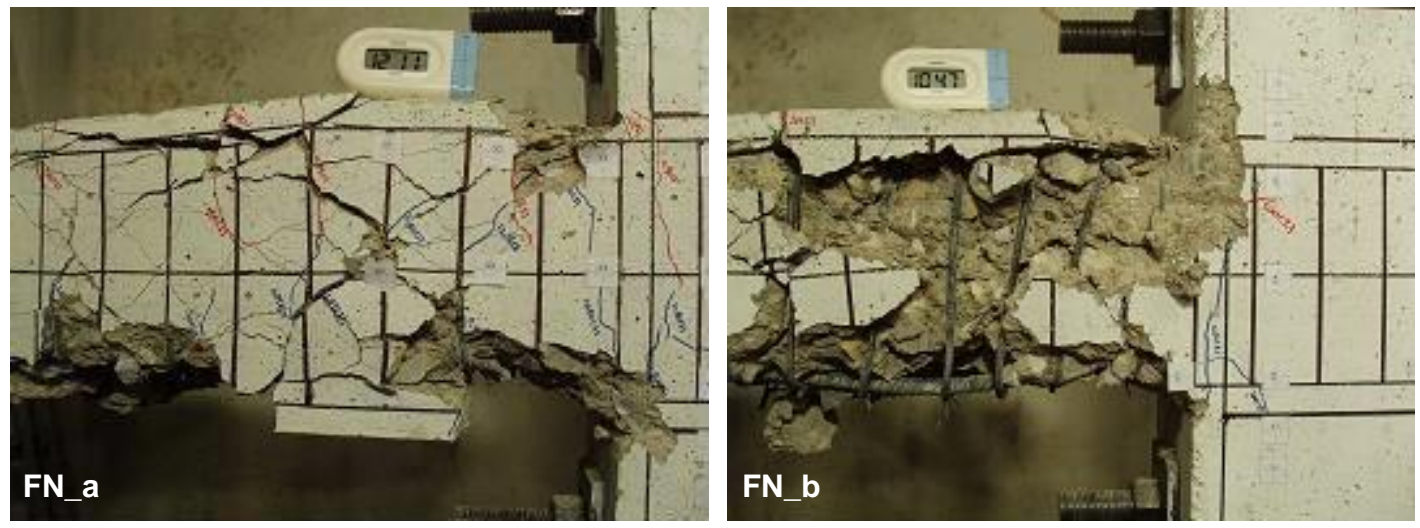

Figure 5 Specimens FN_a and FN_b at failure 

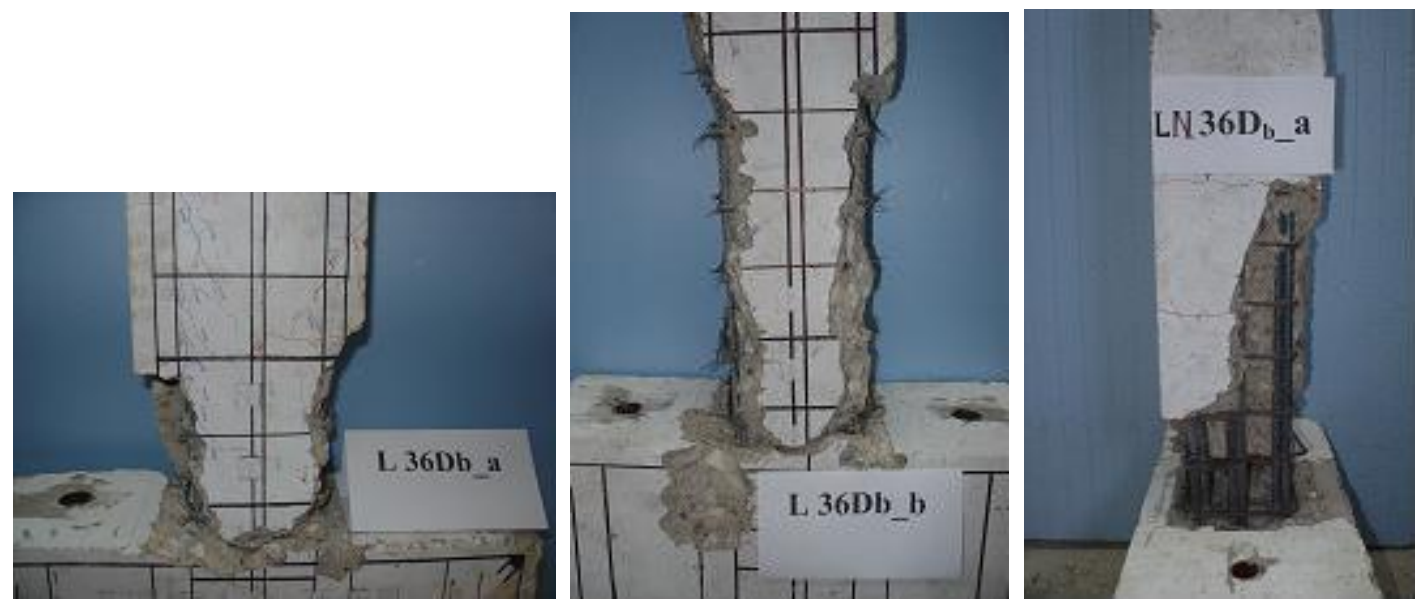

Figure 6 Specimens with lap-splices after removing the loose concrete fragments

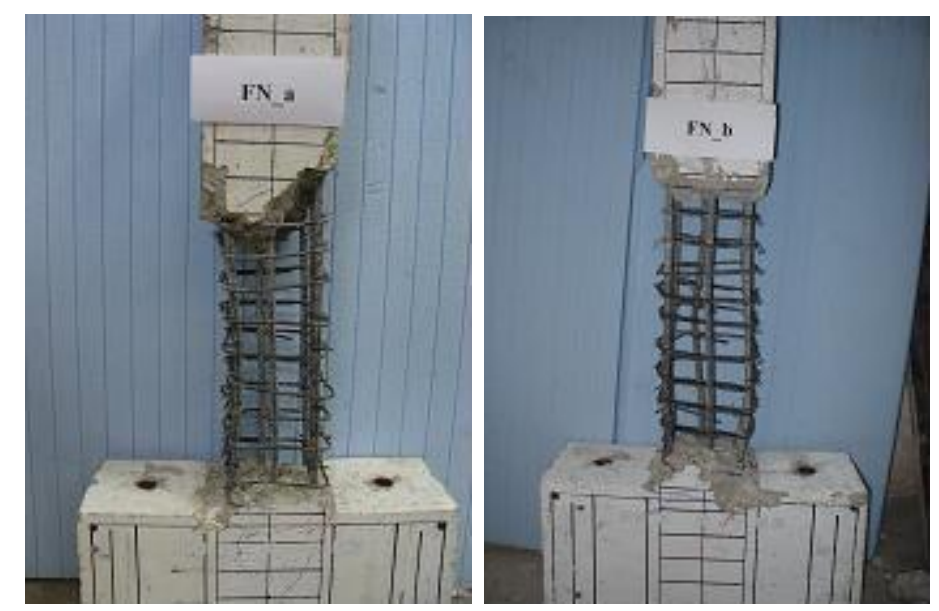

Figure 7 Specimens FN_a and FN_b after removal of damaged and fragmented concrete
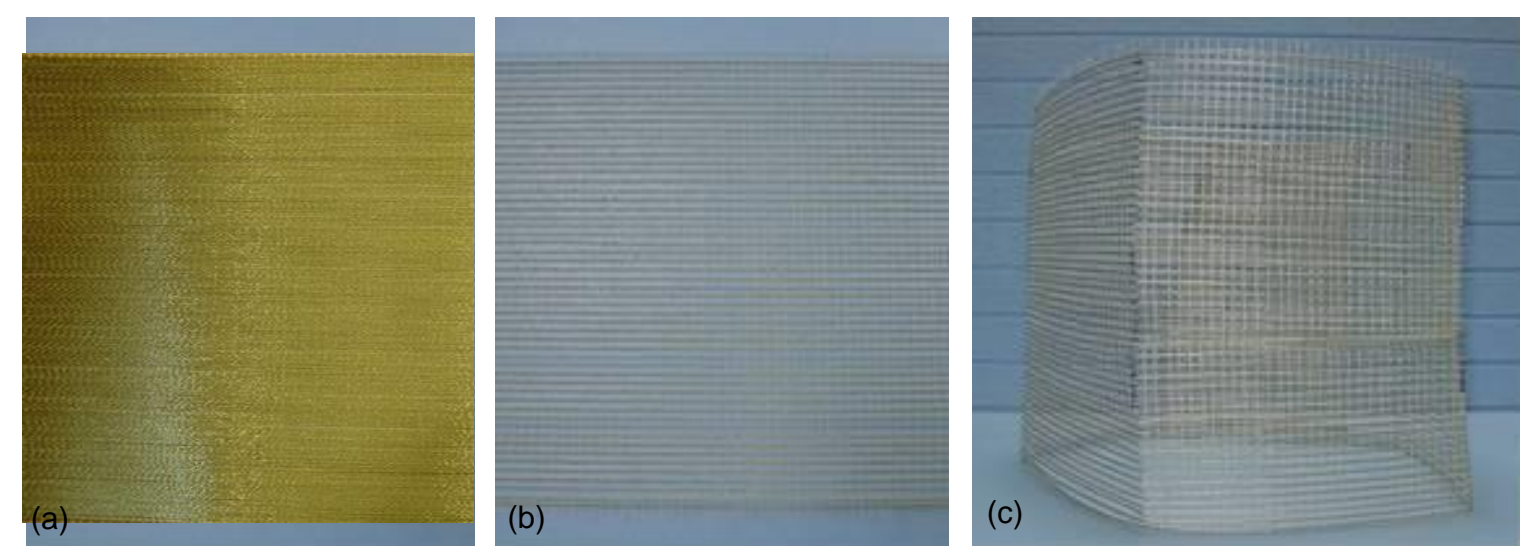

Figure 8 Metallic fabric 12X (a) at initial condition; (b) after modification; (c) jacket 


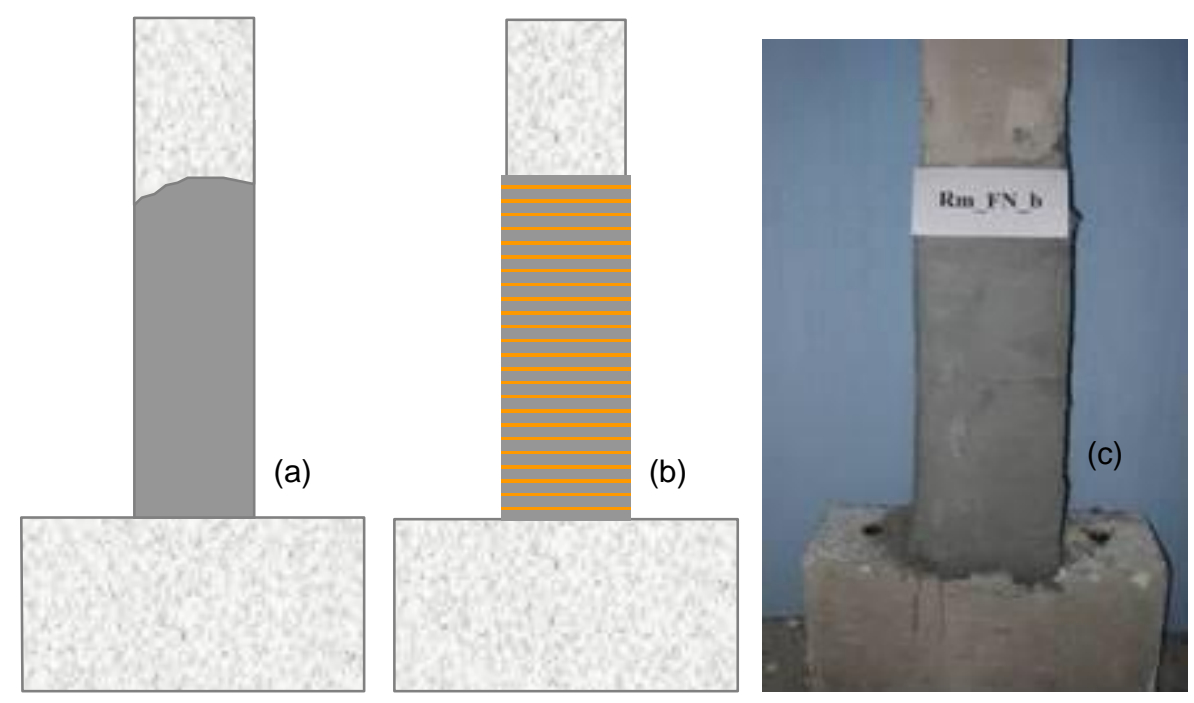

Figure 9 Steps of the method of application
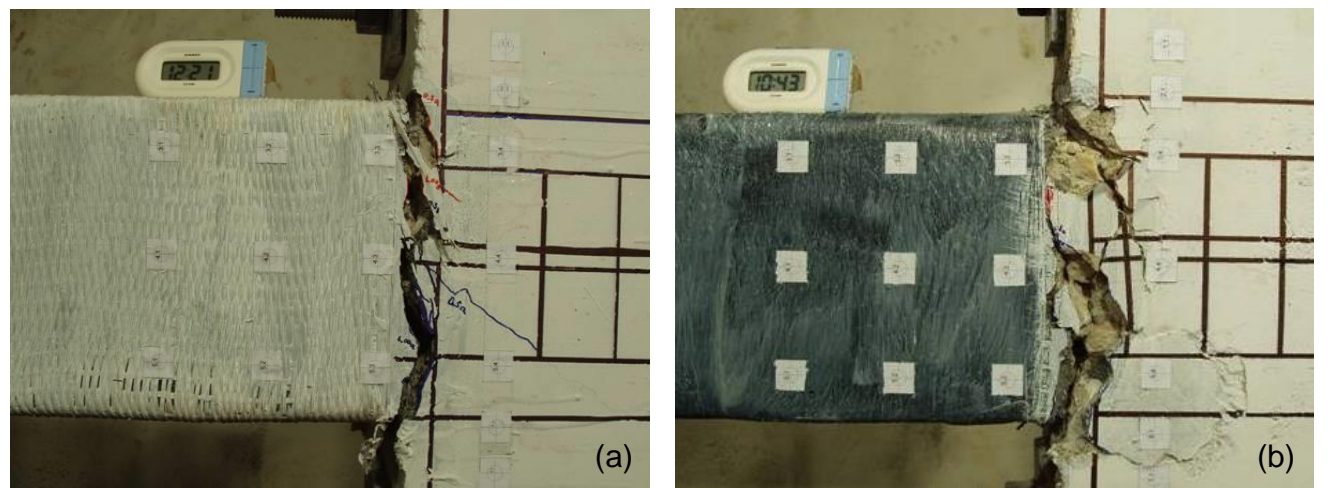

Figure 10 Specimens (a) RgLN36D $D_{b} b$; (b) RcLN36D $D_{b} b$ at failure
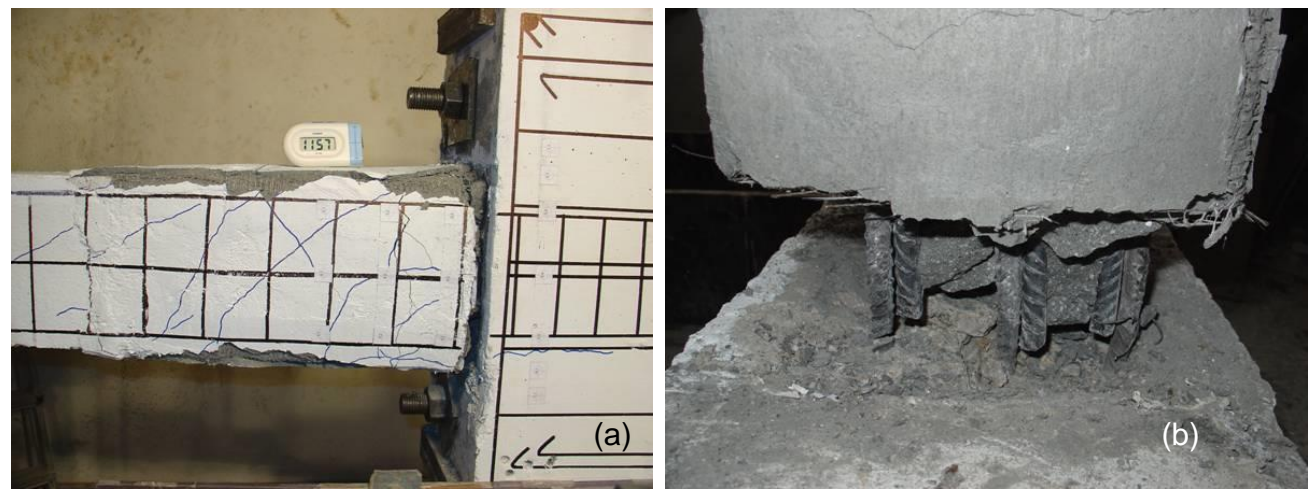

Figure 11 Specimen $R m L N 36 D_{b} \_b$ (a) at failure; (b) detail of the damaged area 

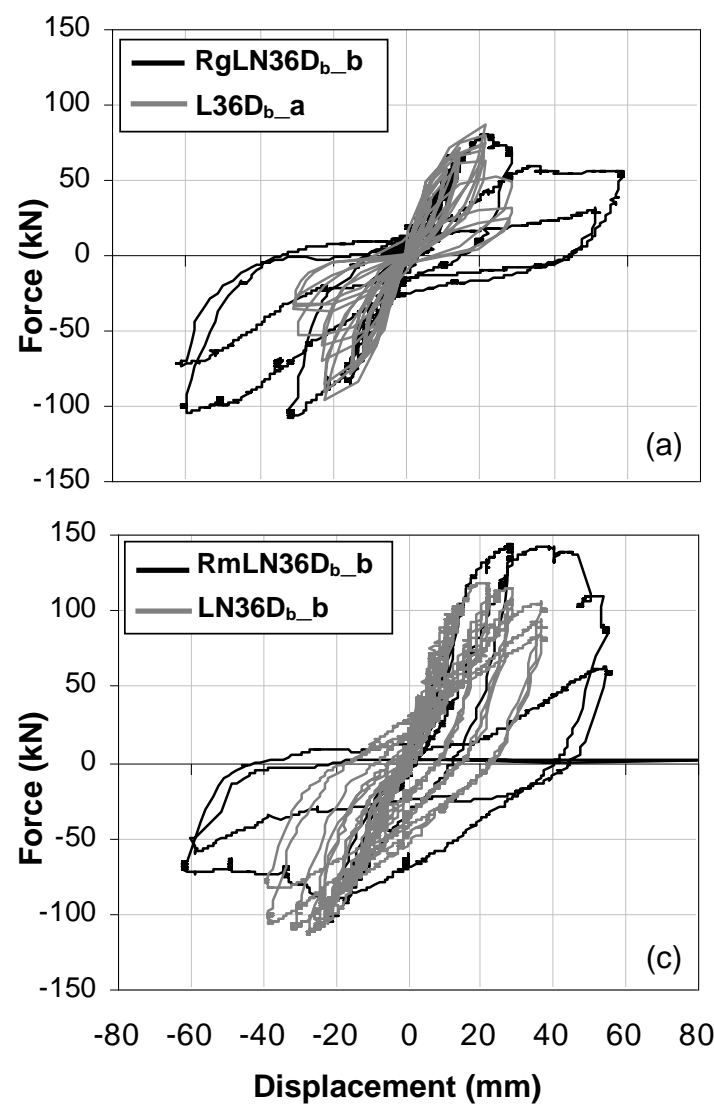

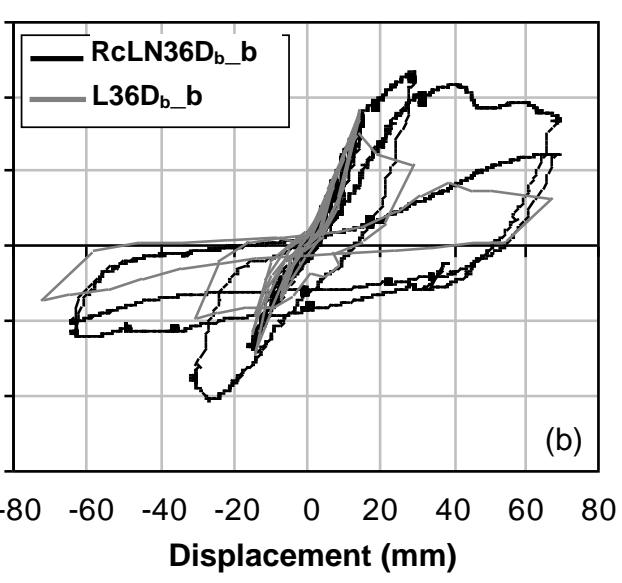

Figure 12 Load-displacement diagrams for the system of specimens Rc-, Rg-, $R m L N 36 D_{b} \_b$ 

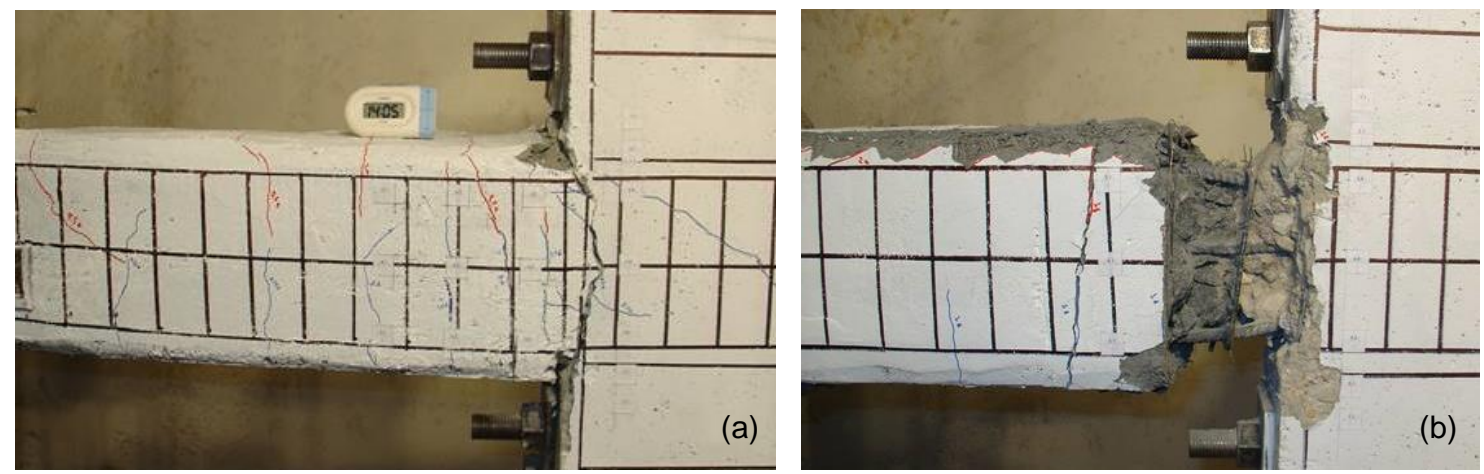

Figure 13 Specimens (a) RmFN_a; (b) RmFN_b at failure
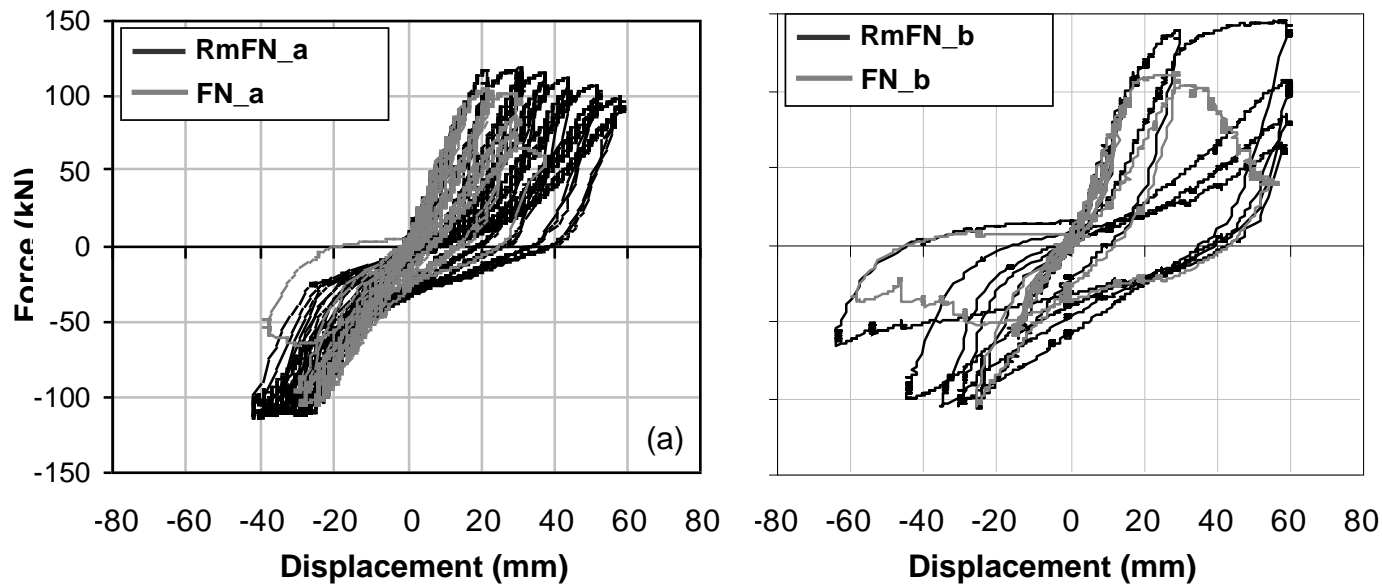

Figure 14 Load-displacement diagrams for the system of specimens RmFN_a and RmFN_b
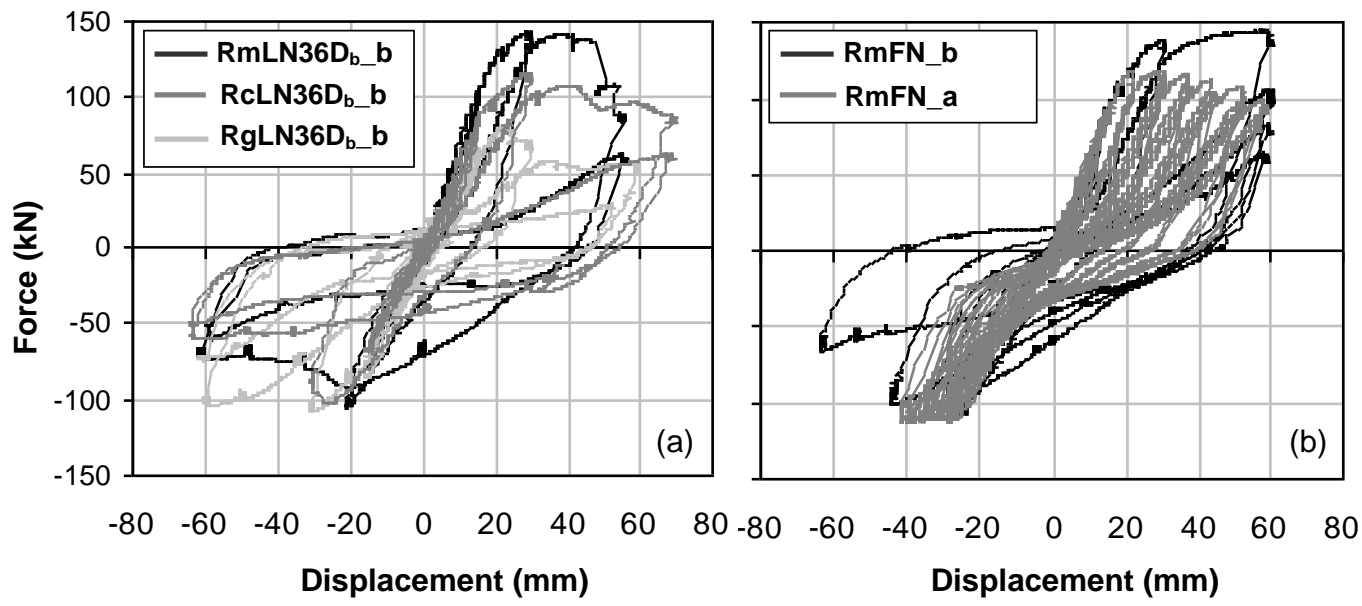

Figure 15 Load-displacement diagrams for the system of specimens (a) Rc-, Rg-, RmLN36D $b$ b; (b) RmFN_a and RmFN_b 


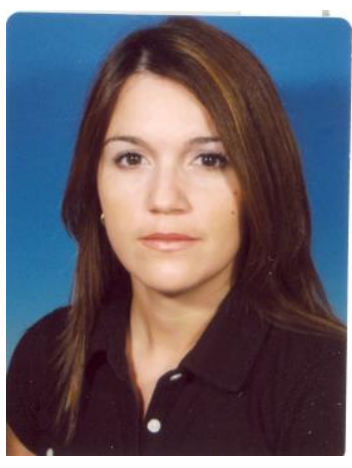

Georgia E. Thermou, PhD Candidate

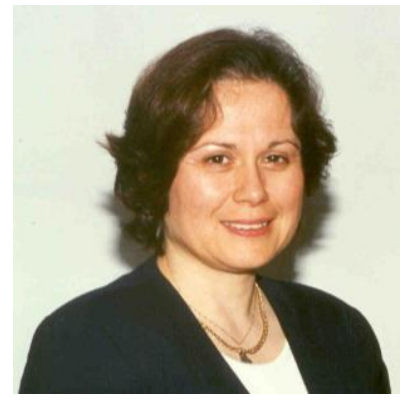

Professor S.J. Pantazopoulou 